\title{
ORGANIZACIÓN JUDICIAL EN EL DERECHO CHILENO: UN PODER FRAGMENTADO*
}

\author{
JUDICIAL ORGANIZATION CHILE: A FRAGMENTED BRANCH
}

\author{
ANDRÉS BORDALÍ SALAMANCA**
}

\begin{abstract}
RESUMEN: El presente trabajo explora la función judicial en el sistema constitucional chileno concluyendo que se debe avanzar desde una función de resolución de la litis a una más compleja y vasta garantía y tutela del ordenamiento jurídico que, en lo fundamental, reclama siempre imparcialidad de juicio. Se examina asimismo el tipo de organización judicial que es recomendable para poder cumplir con éxito la función encomendada a los tribunales de justicia. Se compara el sistema judicial chileno con el español, el estadounidense y el italiano.
\end{abstract}

Palabras clave: independencia judicial, judicatura, Poder Judicial chileno, función judicial, gobierno judicial, imparcialidad judicial, sistema judicial, autonomía judicial, garantía judicial, jurisdicción.

ABSTRACT: This paper explores judicial work in the Chilean Constitutional System, concluding that it must improve from the resolution of legal conflict to a more complex and extended protection of the Juridical System, which, in essence, always demands impartiality in the process. An advisable organization for a successful judicial work is also analyzed. The paper compares the Chilean Judicial Systems with that of Italy, Spain and the United States of America.

Key words: Judicial independence, judiciary, Chilean Judiciary Branch, judicial function, judicial government, judicial impartiality, judicial system, judicial self-government, rights protected in the judicial procedures, jurisdiction.

\section{INTRODUCCIÓN}

Si un extranjero le pidiera a un abogado chileno que enumere los tribunales de justicia que existen en el país, es muy probable que nuestro colega se encuentre en una situación bastante inconfortable, ya que es casi imposible hacer un elenco exhaustivo de los tribunales que tenemos. Junto a los tribunales que conforman el Poder Judicial existe igual o mayor cantidad de ellos ubicados fuera de esta organización.

\footnotetext{
* Este trabajo ha sido realizado en el marco y con el financiamiento del proyecto Fondecyt no 1070211 del que el autor de este trabajo es su investigador responsable. Los estudios referidos al derecho comparado, específicamente estadounidense y español, han contado con la colaboración, respectivamente, de los coinvestigadores Daniela Accatino Scagliotti y Juan Carlos Ferrada Bórquez.

** Licenciado en Ciencias Jurídicas Universidad de Chile, Doctor en Derecho Universidad de Valladolid, Profesor de Derecho Procesal en la Universidad Austral de Chile, Casilla 567, Valdivia, Chile. Correo electrónico: abordali@uach.cl.
} 
A ese extranjero no solo le sorprendería esta proliferación de tribunales, sino también el hecho que este abogado chileno incluya en ese elenco, sin titubeo alguno, a tribunales que pertenecen a los poderes Ejecutivo o al Legislativo. Frente a la perplejidad del extranjero, el abogado chileno posiblemente responderá que no hay ningún problema en ello, puesto que la ley les ha atribuido el poder para resolver conflictos de relevancia jurídica, por lo que no hay duda que son tribunales. Es la función lo que determina al órgano, argumentará. Y agregará que esa función que la ley le encomienda consiste en solucionar la litis. Citará para estos efectos obras generales de Derecho Procesal o Constitucional chilenos y algún fallo de nuestro Tribunal Constitucional para avalar su respuesta.

Sin embargo, si ese extranjero pertenece a una democracia europea o americana y conoce el derecho de su país, podrá objetarle al abogado chileno que los tribunales de justicia hacen más que resolver litis, para describirlos como órganos de garantía de los derechos de los individuos frente al poder político. Y esto último hace inconcebible la consideración de estos órganos adscritos a los poderes políticos representativos (Ejecutivo o Legislativo) como tribunales de justicia.

Del hipotético diálogo reseñado hasta aquí surge la pregunta de cuál es la concepción de la función judicial en el derecho chileno y, por otra parte, surge el cuestionamiento si de una determinada función judicial se desprende una correlativa organización que sea capaz de garantizar la independencia en relación a los poderes políticos que debe concurrir siempre en todo tribunal de justicia ${ }^{1}$. La hipótesis que intentaré justificar en las siguientes páginas dirá que la función judicial en Chile va mucho más allá de la concepción de solución de conflictos para avanzar a la tesis de una función de garantía, todo lo cual exige, además de independencia, una organización judicial basada en los principios de unidad y exclusividad. Para todo ello examinaré cómo se organizan los poderes judiciales en el derecho comparado, especialmente en España, Estados Unidos de Norteamérica e Italia, a fin de realizar una propuesta para el derecho chileno

\section{FUNCIÓN JUDICIAL: ALGO MÁS QUE SOLUCIÓN DE LITIGIOS ENTRE PRIVADOS}

La Constitución Política de la República de Chile de 1980 no define en ninguna parte qué ha de entenderse por función judicial. Solo se refiere en términos muy generales a que "la facultad de conocer de las causas civiles y criminales, de resolverlas y hacer ejecutar lo juzgado, pertenece exclusivamente a los tribunales establecidos por la ley" (Art. 76) ${ }^{2}$. La función de los jueces es, por tanto, según nuestro texto constitucional, conocer y resolver causas civiles y criminales, y hacer ejecutar lo juzgado.

\footnotetext{
${ }^{1}$ Para una justificación de la independencia como característica inherente y definitoria de la jurisdicción, remito a anteriores trabajos y que se enmarcan en este mismo proyecto de investigación: BorDALí (2007a); BORDALÍ (2007b) y BORDALí (2008), passim.

${ }^{2}$ En similares términos de refería la Constitución de 1833 en su artículo 108 y la Constitución de 1925 en su artículo 80 .
} 
La disposición constitucional precedentemente citada suscita más de una duda interpretativa. Así, no solo surge una incertidumbre interpretativa en lo que dice relación con las actividades de conocer y resolver, sino también respecto al ámbito material de las causas que debe conocer y resolver, esto es, qué ha de entenderse por causas civiles y criminales. En mi concepto, esta última denominación no debe ser interpretada restrictiva y literalmente, sino que debe ser entendida como una fórmula general que involucra a todas las cuestiones jurídicas que deben ser conocidas por los tribunales de justicia y que no estén encomendadas por la propia Constitución a órganos específicos. Si se usó la expresión causas civiles y criminales ello obedece a razones históricas, pues es la fórmula que se utilizaba habitualmente a principios del siglo XIX en el derecho comparado $^{3}$ y que expresaba el tipo de asuntos que conocían los tribunales de justicia. Hay que tener presente que en el derecho continental de principios del XIX los tribunales solo conocían del contencioso civil y criminal, no existiendo un contencioso judicial administrativo ni constitucional. Con el correr del tiempo, como sabemos, la jurisdicción, en cuanto poder independiente de los poderes políticos representativos comenzó a conocer de cuestiones administrativas y constitucionales. Esa misma evolución se ha dado en el derecho chileno, la que, sin embargo, no se refleja en la fórmula que utiliza hasta el día de hoy el artículo 76 CPR.

De este modo, la fórmula que utiliza el artículo 76 CPR debe ser entendida como una cláusula general de jurisdicción que recae en todo tribunal de justicia establecido por ley, salvo que sea la propia Constitución la que reserve una materia a un tribunal especial, como ocurre con el Tribunal Constitucional.

La mayor apertura de la fórmula empleada por nuestra Constitución se produce por el lado del concepto "causas civiles". Habitualmente se entiende por estas como todas aquellas que no son criminales, cualquiera sea el tribunal que conozca de ellas. Por lo tanto se podría decir que el concepto de "causas civiles" incluye aquellas estrictamente civiles referidas a conflictos entre privados y regidas por códigos y leyes de derecho privado (Código Civil, Código de Comercio, otros códigos y leyes especiales) así como aquellas civiles en un sentido amplio donde se pueden incluir todas las que no caen en una definición estricta de causa civil ni tampoco criminal, pudiendo incluirse las laborales, tributarias, de minería, administrativas ${ }^{4}$, etc.

Aclarado el punto anterior, se debe determinar en qué consiste la función de conocer y resolver esas causas judiciales. Entrando a analizar las actividades que según la Constitución realizan los tribunales de justicia, cabe indicar que en Chile es común

\footnotetext{
${ }^{3}$ Un referente es la Constitución de Cádiz de 1812 que disponía en su artículo 242 que "La potestad de aplicar las leyes en las causas civiles y criminales pertenece exclusivamente a los tribunales".

${ }^{4}$ Para nuestro Tribunal Constitucional deben considerarse causas civiles los asuntos que resuelve la Administración del Estado y que afectan derechos de las personas. En efecto, ha señalado el Tribunal Constitucional "que dentro del concepto 'causas civiles' a que se refiere la disposición preinserta [Art. 76 CPR], se deben incluir todas aquellas controversias jurídico-administrativas que se pueden suscitar, y que deben resolver autoridades, que si bien no están insertas dentro de los tribunales que regula el Código Orgánico de Tribunales, están ejerciendo jurisdicción y resolviendo cuestiones que afectan los derechos de las personas". Sentencia rol no $176 / 1993$.
} 
entender los conceptos de conocer y resolver ${ }^{5}$ las causas civiles y criminales como sinónimos de resolver conflictos jurídicos del orden temporal. La propia jurisdicción es definida comúnmente como el poder-deber que tienen los tribunales para conocer y resolver por medio del proceso y con efectos de cosa juzgada los conflictos de intereses de relevancia jurídica que se promueven en el orden temporal, dentro del territorio de la República y en cuya solución les corresponde intervenir ${ }^{6}$. De este modo, se entiende que la función judicial consiste en resolver conflictos de relevancia jurídica del orden temporal. Dicho de otra manera, la función de los tribunales de justicia consiste en resolver por medio del proceso la confrontación de pretensiones y resistencias o un conflicto intersubjetivo de intereses. Sin embargo, a estas alturas de evolución de la dogmática procesal ya sabemos que esta concepción de la función judicial no es exacta, pues la doctrina hace años que pone atención en que hay muchas actuaciones jurisdiccionales que no presuponen un conflicto de intereses o al menos se discute la existencia del mismo. Los ejemplos son muchos. Van desde la inexistencia de un conflicto de intereses en el campo penal ${ }^{7}$, a los procesos civiles que crean, modifican o extinguen relaciones jurídicas ${ }^{8}$, lo que algunos denominan actos de jurisdicción de contenido objetivo ${ }^{9}$. Pero en el campo civil también está el problema de los procedimientos meramente declarativos donde la actividad jurisdiccional no conoce al menos de un conflicto de intereses presente. A lo más podría pensarse en este caso que el proceso previene un eventual conflicto futuro.

Y luego están los procesos no propiamente civiles de que conocen algunos tribunales civiles, como en el caso de control de juridicidad de determinadas actuaciones de órganos del Estado, como ocurre en Chile con la denominada nulidad de derecho público. En esta es bastante dudoso entender que hay un conflicto de intereses intersubjetivo. Los ejemplos podrían multiplicarse. De este modo parece aconsejable no interpretar las actividades de conocer y resolver referidas a un conflicto de intereses. Los tribunales resuelven en muchos casos conflictos, pero hacen más que eso.

Por otra parte, siguiendo la tesis de la función judicial como resolución de conflictos, se podría producir un problema para el Estado de Derecho y que consiste en que la resolución de conflictos también podría ser encomendada por el legislador a órganos

\footnotetext{
${ }^{5}$ Debe ser criticada esta descripción de actividades que realizan los tribunales de justicia. En algunos casos se peca por reiteración y en otros por omisión. Si los tribunales tienen el poder de resolver un determinado asunto, se sobreentiende que tienen el poder de conocer. No se puede resolver si no se tiene reconocido previamente el poder de conocer. Por lo tanto la fórmula debería haberse limitado a indicar que se tiene el poder de resolver. En este sentido era menos tautológica la Constitución de Cádiz de 1812 que en su artículo 245 señalaba que los tribunales no podrán ejercer otras funciones que las de juzgar y hacer ejecutar lo juzgado. Pero la fórmula del artículo 76 CPR omite a su vez una importantísima función de los tribunales de justicia, cual es la asegurativa o cautelar. Se trata de que los tribunales deben tener el poder para obviar los peligros que pueden comprometer el resultado del proceso durante el tiempo que se necesita para obtener la tutela jurisdiccional.

${ }^{6}$ Colombo (2004) p. 45.

7 RICCI (2001) p. 6.

${ }^{8}$ Cita obligada sobre este aspecto es GUASP (1985) pp. 26 y ss.

${ }^{9}$ MANDRIOLI (2000) p. 14.
} 
que no sean propiamente tribunales de justicia. Sin embargo, aquella función resolutoria encomendada por la ley convertiría a esos órganos, del tipo que sean, en tribunales de justicia, lo que viene a comprometer la finalidad de la separación de los poderes en un Estado de Derecho. Se puede fácilmente intuir que no da lo mismo que, por ejemplo, los delitos terroristas sean conocidos y resueltos por un Tribunal de Juicio Oral en lo Penal que por el Ministro del Interior, un Gobernador o Prefecto de Investigaciones, por mucho que la ley los facultara para resolver esas materias. Hay que entender que lo que se busca con la actividad jurisdiccional es la decisión de los asuntos de relevancia jurídica con total imparcialidad, cumpliendo fielmente el mandato de la ley y no poniéndose de lado de los intereses económicos, personales, políticos o del tipo que sean de algunas de las partes de la causa. Este es el sentido de reconocer constitucionalmente el monopolio jurisdiccional en cabeza de los tribunales de justicia establecidos por el legislador.

La doctrina ha intentado en múltiples oportunidades explicar materialmente qué hacen los tribunales de justicia con distintas teorías, incluida la muy difundida en Chile de resolución de los conflictos intersubjetivos o de la litis. Sin embargo, todas ellas no permiten explicar lo propio del fenómeno jurisdiccional. Gian Franco Ricci ${ }^{10}$ resume las teorías dadas durante el siglo XX en Italia, que son quizá las más conocidas no solo en Italia sino también en España e Iberoamérica. Reseña este autor que Chiovenda a principios del siglo XX intentó dar una respuesta general a la pregunta por la función judicial que intentara revertir las críticas que se formulaban a las teorías predominantes hasta este entonces, como lo eran la de resolución de la litis, así como la teoría de la reintegración de los derechos subjetivos, que no permiten explicar el fenómeno jurisdiccional donde no hay tales derechos subjetivos, como en el proceso penal, el proceso civil objetivo, el proceso administrativo dispuesto a la tutela solo de intereses legítimos y no de derechos subjetivos, etcétera.

La teoría de Chiovenda expresaba que lo que hacen los tribunales es actuar la ley. Todo tribunal de justicia lo que hace es actuar la ley, sea civil, penal, laboral administrativa, etcétera, con lo cual se despejaron las críticas antes apuntadas respecto a la teoría de la resolución de la litis y de reintegración de los derechos subjetivos. Sin embargo, la doctrina destacó que en algunos casos la Administración también actúa la ley, por lo que la respuesta de Chiovenda no permite establecer diferencias entre ambas funciones estatales.

Otros -sigue explicando Ricci- como Redenti intentaron sostener la tesis que lo propio de los tribunales es irrogar sanciones, pero nuevamente se dieron cuenta que la Administración, a fin de tutelar algún interés público, también estaba facultada para irrogarlas. Y además está la situación de aquellos procesos que no imponen sanciones, como el proceso civil constitutivo y el meramente declarativo. Así, otros autores intentaron ver lo propio del fenómeno jurisdiccional en la irrevocabilidad de la decisión judicial o el efecto de cosa juzgada. La función judicial se explicaría no materialmente, sino por los efectos que produce. Es jurisdiccional de este modo cualquier decisión de un órgano en la medida que sea irrevocable.

${ }^{10}$ RICCI (2001) pp. 5 y ss. 
La tesis de la irrevocabilidad como característica de la jurisdicción es bastante aceptada hoy en día tanto en el derecho comparado como en Chile. De hecho en la definición que se usa habitualmente en Chile de la jurisdicción, según apuntamos más arriba, se combina la teoría de la resolución de la litis con los efectos de cosa juzgada. Pero esta teoría no es exacta ni completa. No es exacta porque el fenómeno procesal admite excepciones al efecto de la irrevocabilidad. Piénsese que en Chile una decisión judicial penal que ha adquirido la calidad de ejecutoriada puede ser revisada por la Corte Suprema sin límite de tiempo, si algún afectado hace valer algunas de las causales de revisión que la ley reconoce. En materia civil se encuentra más restringida esta revisión, ya que existe un plazo de un año para hacerla valer desde que la sentencia judicial se encuentra ejecutoriada. Se podrá rebatir que en estos casos no hay cosa juzgada porque se dictó una sentencia injusta, con base en errores o medios de prueba falsos. Pues entonces se debería señalar que las sentencias de los tribunales de justicia producen el efecto de cosa juzgada bajo condición que dichas sentencias sean justas, verdaderas o no fraudulentas, lo que en parte, cabe admitir, viene a relativizar el efecto de cosa juzgada de los tribunales de justicia.

Luego está el tema de los actos procesales intermedios, como los de iniciación del proceso, los que le dan curso progresivo, las medidas cautelares, etcétera. Es claro que estos no producen el efecto de cosa juzgada, pero nadie osaría en señalar que no son jurisdiccionales. En estos casos se podrá hablar de actividad jurisdiccional por conexión, pues aparecen conectados con la decisión de derecho irrevocable. Se trata de actos que por sí solos no tienen ninguna autonomía ${ }^{11}$.

Por otra parte, como lo hace ver en España Juan Luis Requejo ${ }^{12}$, hay que entender que toda aplicación de normas jurídicas presenta la característica de la irrevocabilidad y, como se sabe, no solo la jurisdicción aplica normas sino también la Administración. Lo que ocurre es que las decisiones de la jurisdicción presentan el mayor grado de irrevocabilidad posible. No se trata entonces de una diferencia esencial, sino de grados o matices.

Lo interesante de la tesis de Requejo es que la idea de irrevocabilidad llevará a la de independencia que debe estar siempre presente en la actividad jurisdiccional. La vinculación entre irrevocabilidad e independencia estriba en que por razones de legitimidad los actos de aplicación irrevocable del derecho deben ser producidos por un órgano sometido estrictamente al principio de legalidad. Todo acto de aplicación de normas debe regirse por este principio, pero será especialmente relevante tratándose de aquellos órganos cuyas decisiones adquieren el mayor grado de irrevocabilidad posible, como ocurre con los tribunales de justicia. Ahora bien, para asegurar que los órganos jurisdiccionales acatarán el principio de legalidad se requiere que estos sean independientes. De este modo, con la independencia se asegura el acatamiento y al mismo tiempo defensa del ordenamiento jurídico y no la sumisión a determinados sectores políticos o sociales.

\footnotetext{
${ }^{11}$ Martínez Alarcón (2004) p. 35.

12 REQUejo (1989) pp. 75 y ss.
} 
Requejo llega a sostener que el verdadero cometido de los órganos jurisdiccionales no estriba tanto o no lo hace principalmente en alcanzar fines tales como la solución de controversias o la satisfacción de pretensiones, ni siquiera la paz social, sino en asegurar en todo caso la pervivencia del sistema jurídico. Y es en atención de este fin por lo que solo los órganos jurisdiccionales independientes pueden dictar actos irrevocables ${ }^{13}$.

Ferrajoli últimamente ha sostenido que a los tribunales de justicia les corresponde, a diferencia de una función de gobierno que diseña y decide el espacio de la política, una función de garantía, y en concreto, una función de garantía secundaria; esto es, desarrollan la función de establecimiento y sanción o reparación de la violación de una garantía primaria ${ }^{14}$.

A diferencia de la función de gobierno que en un Estado democrático de derecho encuentra su legitimidad en la voluntad popular, la función judicial en cuanto garantía la encuentra en la verdad, ya que lo que hace justa o injusta una decisión judicial es solo su aceptabilidad como verdadera, que a su vez depende de la correcta aplicación sustancial de la ley por cuyo trámite solo se da la mediación entre jurisdicción y voluntad popular. Esto explica por qué las funciones de gobierno y de garantía deben estar separadas. Los jueces y tribunales garantizan los derechos de todo el pueblo y no de mayorías, grupos o sectores. Es que su rol de garantía es esencialmente contramayoritario, por lo que deben poder decidir, en algunos casos, aun contra la voluntad de la mayoría, especialmente cuando deben tutelar derechos fundamentales ${ }^{15}$.

Esa necesidad de independencia Ferrajoli la vincula también a la función de control de las ilegalidades del ejercicio de los poderes públicos. Por ello, la función judicial se configura como un contra-poder, dispuesto al control del ejercicio ilegal de los otros poderes, sin que pueda por ello interferir en sus competencias: Los jueces no pueden actuar sobre los espacios legítimos de la política y de la economía, sino solo sobre sus espacios ilegítimos que se manifiestan en actos inválidos o en actos ilícitos ${ }^{16}$.

Cabe destacar en relación a la función judicial que durante el siglo XIX se la entendió en una dirección vertical desde el Estado hacia los ciudadanos. De ahí la fórmula, como se analizaba precedentemente, de "causas civiles y criminales" a que se refiere hasta el día de hoy nuestra Constitución (art. 76). Esas son las causas que normalmente conoce la jurisdicción. Pero desde fines del siglo XIX y principios del siglo XX, al menos en la mayoría de las democracias europeas, la función judicial ya no solo es vertical en el sentido de resolver los tribunales las disputas entre los ciudadanos o de establecer la comisión de un delito por un ciudadano, sino que esa función asume una dimensión horizontal, de poder contra poder, como ocurre con el contencioso administrativo y legislativo.

Y lo relevante de esta evolución enjuiciadora vertical hacia una de tipo horizontal es cierta "maldad política", como lo denomina Alejandro Nieto ${ }^{17}$ en España, en el sentido de que si los jueces, como antes, solo se ocuparan de arrendamientos rústicos,

\footnotetext{
13 REQUeJo (1989) pp. 138 y 139.

${ }^{14}$ FerRajoli (2007a) pp. 872 y ss.

15 Ferrajoli (2007b) p. 216.

${ }^{16}$ Ferrajoli (2007b) p. 216.
} 
letras de cambio y hurtos callejeros, seguro que el poder político respetaría la independencia de los jueces sin necesidad de garantía constitucional alguna. Pero en la medida que los funcionarios estatales pueden ser enjuiciados por actos de corrupción, o desde que determinados actos del Gobierno o del Poder Legislativo pueden ser anulados por un tribunal de justicia, a los poderes políticos, especialmente al Ejecutivo, les interesa poder interferir sobre esos jueces. Los medios de intervención pueden ser de varios tipos. Se trata obviamente de intervenciones en la mayoría de los casos legales, aunque no está muy claro que sean constitucionales.

Si miramos en el caso de Chile, la "maldad política" de que habla Alejandro Nieto consiste en reservar a la Administración el conocimiento de determinados asuntos en los que aparecen involucrados esa Administración y los ciudadanos, como ocurría ${ }^{18}$ hasta hace poco en el contencioso tributario y aduanero, pero que permanece todavía en algunas situaciones donde un agente del Gobierno o de la Administración puede resolver un determinado asunto como si fuera un verdadero juez. Esa es quizá la vulneración más grosera de la independencia judicial. Hay otras más sutiles como ocurre con la designación por parte del Ejecutivo de los jueces y abogados integrantes que le proponen las Cortes de Apelaciones y la Corte Suprema. Es evidente que tal sistema se presta para que el Ejecutivo nombre a personas de su agrado ideológico o político dentro de las posibilidades que le ofrecen los órganos judiciales. Ello es especialmente relevante en el caso de los ministros y abogados integrantes ${ }^{19}$ de las Cortes de Apelaciones, los que conocen en muchos casos de las reclamaciones que se pueden interponer contra las decisiones de los agentes administrativos obrando como jueces de primera instancia del contencioso administrativo. Tenemos de este modo a la Administración fallando en primera instancia en causa propia y luego a una Corte de Apelaciones cuyos miembros, titulares y abogados integrantes, han sido designados por el propio Ejecutivo.

Con un carácter general que mira a la experiencia comparada y en una perspectiva histórica, se puede decir que aquellas controversias que tienen un marcado impacto político generalmente se le sustraen al juez ordinario y se le encargan a un juez especial, al cual es común que se le atribuyan garantías de independencia más atenuadas y por tanto con mayor cercanía con el poder político, especialmente del Ejecutivo ${ }^{20}$.

\footnotetext{
17 NiETO (2005) p. 123.

${ }_{18}$ Me refiero en pasado a esta situación debido a que el Poder Legislativo entendió finalmente que los órganos que conocían del contencioso tributario y aduanero no eran verdaderos tribunales de justicia. Dictó de este modo la Ley sobre Tribunales Tributarios y Aduaneros (Ley 20.322), aunque todavía no están en funcionamiento dichos tribunales. La decisión del legislador es destacable, ya que el Tribunal Constitucional se había pronunciado que dichos órganos no presentaban ningún tipo de problema constitucionalidad para la resolución del contencioso tributario y aduanero, respectivamente. Parece ser que el órgano legislativo escuchó más en esta materia a la doctrina tributarista y alguna de carácter procesal antes que al máximo tribunal defensor de la Constitución.

${ }^{19}$ Especialmente delicada es la situación de los abogados integrantes de las Cortes de Apelaciones, que solo duran un año en su cargo (Art. 219 inc. 20 COT) y si quieren ser nombrados nuevamente por el Ejecutivo, podrían sentirse inclinados a fallar a favor del Gobierno y de la Administración en las causas que lleguen a su conocimiento y decisión.

${ }^{20}$ GUARNieri y PEDERZOLI (2002) p. 22.
} 
A juicio de Guarnieri y Pederzoli ${ }^{21}$, contra más fragmentada la jurisdicción en el sentido de crear jueces especiales junto a los ordinarios, menor es la incidencia de la justicia en la política. O lo que es lo mismo, es mayormente difícil que se cumpla la función de garantía de los tribunales de justicia. En concepto de estos autores italianos, quizá sea España en Europa (desde la Constitución de 1978) el país con mayor unidad jurisdiccional $^{22}$, lo que es efectivo según analizaremos más adelante, por lo que se podría deducir o suponer que es en este país donde mejor pueda realizarse la función judicial en cuanto garantía o tutela del ordenamiento jurídico en su conjunto. Sin embargo, países con una organización judicial en algún sentido fragmentada como ocurre con los Estados Unidos de Norteamérica también gozan de una alta independencia judicial pudiéndose realizar con solvencia la función de garantía de los derechos, por lo que, más adelante, se deberán hacer algunas matizaciones a la tesis de estos autores.

De lo dicho hasta acá es de destacarse que no parece ser exacta ni completa aquella explicación de la función judicial como resolución de conflictos de relevancia jurídica que se utiliza habitualmente en la doctrina y jurisprudencia chilenas. Si a ello se agrega una pretendida concepción de que esas controversias que resuelven los tribunales de justicia solo son aquellas "civiles y criminales", el problema se acrecienta aún más porque se da a entender que los jueces se limitan a resolver esa litis donde aparecen involucrados solo los intereses de los ciudadanos, dejando de lado las controversias donde aparecen afectados los intereses de los órganos políticos y la necesidad de tutela del propio ordenamiento jurídico frente a dichos poderes políticos, que es lo que justifica con mayor incidencia la necesidad de independencia judicial.

Quizá debido a esta concepción de la función judicial es que en Chile no haya existido mayormente ninguna preocupación sobre el hecho que muchas leyes consideren a la Administración como juez de primera instancia en algunos asuntos en los que aparece involucrada ella misma, lo que claramente afecta a la función de garantía que deben cumplir los tribunales de justicia en un Estado de Derecho. De hecho la función judicial de resolver las disputas entre ciudadanos y Administración aparece disgregada de la cláusula general de la función judicial a que se refiere el artículo $76 \mathrm{CPR}$. En efecto, es el artículo 38 inciso $2^{\circ} \mathrm{CPR}^{23}$ el que se refiere a este aspecto dentro del Capítulo IV referido al Gobierno, y en particular el acápite referido a las Bases generales de la Administración del Estado.

Concluyo señalando que la función judicial debe entenderse ligada a la determinación irrevocable del Derecho o, lo que es lo mismo, la función de los jueces es la defensa o garantía del Derecho que han creado los poderes políticos. Para que puedan cumplir eso rol los jueces deben organizarse en su conjunto como un poder indepen-

\footnotetext{
21 Guarnieri y PEDERzoli (2002) p. 22

22 Guarnieri y Pederzoli (2002) pp. 22 y 23.

23 Esta disposición establece que "cualquier persona que sea lesionada en sus derechos por la Administración del Estado, de sus organismos o de las municipalidades, podrá reclamar ante los tribunales que determine la ley, sin perjuicio de la responsabilidad que pudiere afectar al funcionario que hubiere causado el daño". Sobre el significado de esta cláusula dentro del sistema constitucional chileno remito al trabajo de Bordalí y FERrada (2008) pp. 140-144.
} 
diente para la imparcial aplicación de ese Derecho. A esos fines de independencia e imparcialidad contribuye el modo como se organiza la judicatura, según pasaremos a revisar a continuación.

\section{DE LA UNIDAD A LA FRAGMENTACIÓN JURISDICCIONAL: EL CASO DE CHILE}

\section{Cuestiones Generales}

En la formación de las democracias europeas se aspiró a un poder judicial unitario que con exclusividad desarrollara la función judicial. Esa aspiración no logró concretarse durante el siglo XIX y ni siquiera en la primera parte del XX. Solo después de la Segunda Guerra Mundial se pudo concretar. Tal organización judicial tenía por objetivo, por una parte, lograr una aplicación de la ley de un modo más igualitario, con el fin de evitar que determinados ciudadanos o grupos fueran enjuiciados por tribunales especiales que dieran un trato más favorable o desfavorable a ellos, según sea el caso. Por otra parte, la idea de un poder judicial unitario pretendió consolidar la separación entre poderes y hacer de la jurisdicción un poder realmente autónomo al modo de un baluarte ante las influencias de los poderes políticos.

Sin embargo, la independencia judicial se logró de dos maneras diferentes. Una de ellas apunta a la independencia individual del juez. Se trata de nombrar a los jueces de un modo tal que no se sientan comprometidos en el desarrollo de su función por los órganos que lo designaron y, por otra parte, asegurando que mientras desarrollen adecuadamente su función no se tomen represalias por el modo como interpretan y aplican la ley. Nos referimos en este último aspecto a la inamovilidad judicial. De esta manera este modelo centra las garantías de independencia en la persona individual del juez. Otra manera de garantizar la independencia judicial apunta a la necesidad de algo más que la pura independencia individual de cada juez. Así se dice que garantizando la autonomía al orden jurisdiccional en su conjunto se puede lograr de mejor modo la independencia que se refiere a cada juez en particular ${ }^{24}$. Frente a los poderes políticos activos se formaría una especie de poder corporativo que arropa a cada juez en el desarrollo de sus tareas jurisdiccionales. Este modelo corresponde a la Europa de la postguerra y sus consejos de la judicatura que gobiernan al Poder Judicial (Francia, Italia, entre otros), los que luego se expandieron por otros países europeos y latinoamericanos.

En esta última tesis, para que el principio de unidad jurisdiccional tenga eficacia para los fines de autonomía e independencia, se requiere que todos los tribunales estén bajo el gobierno de un mismo órgano y regidos por un mismo estatuto orgánico. En este sentido debe entenderse que la función judicial solo puede ser desarrollada por los tribunales que integran el denominado Poder Judicial, los que a su vez se encuentran organizados por un solo órgano de gobierno de carácter autónomo respecto de los demás poderes políticos.

\footnotetext{
${ }^{24}$ BONifacio y GiacobBe (1986) p. 7.
} 


\section{ORgANiZACiÓN JUdicial EN CHILE}

En Chile, el ejercicio de la jurisdicción no está encomendado al Poder Judicial. Pero esta afirmación debe ser entendida en un doble sentido. Primeramente debe señalarse que en ningún sistema judicial comparado la jurisdicción se ejerce por el Poder Judicial. En Chile sucede lo mismo. La jurisdicción se ejerce por los tribunales de justicia. Lo que diferencia al caso de Chile de otros países, como veremos, es que solo algunos de los tribunales que ejercen la jurisdicción pertenecen a la estructura estatal denominada Poder Judicial. En efecto, la Constitución de 1980 no atribuye el ejercicio de la función judicial como pareciera indicar el Título VI del texto constitucional al Poder Judicial, sino que la atribuye a todo órgano creado por ley y denominado por esta como tribunal. Pero tampoco esos tribunales que ejercen la jurisdicción deben pertenecer a la estructura estatal denominada Poder Judicial. La pertenencia o no pertenencia al Poder Judicial no es un requisito constitucional para el ejercicio de la jurisdicción. Tan legítima en este sentido es la actividad de un tribunal perteneciente al Poder Judicial como del que no lo es. Y en su conjunto, son más los tribunales que están fuera del Poder Judicial que los que están adentro de este ${ }^{25}$. Piénsese en el Tribunal Constitucional, el Tribunal Calificador de Elecciones, los tribunales electorales regionales, los Juzgados de Policía Local, los tribunales tributarios y aduaneros que reemplazarán a los Directores Regionales del Servicio de Impuestos Internos y la Junta General de Aduanas, respectivamente, el Tribunal de Defensa de la Libre Competencia, los tribunales militares en tiempos de guerra, el Tribunal de la Contratación Pública, el Tribunal Arbitral de Propiedad Industrial, el Tribunal Arbitral del DL 1939, el Panel de Expertos de la Ley General de Servicios Eléctricos, el Subcontralor General como Juez de Cuentas y el Tribunal de Segunda Instancia del juicio de cuentas regulados en la Ley no 19.908 sobre la Contraloría General de la República, entre otros. Se trata de un elenco no exhaustivo al que se podrían agregar aquellos órganos que no son nominados formalmente tribunales de justicia y que pertenecen derechamente al Gobierno o a la Administración del Estado pero que se entiende por la doctrina y jurisprudencia que ejercen jurisdicción, como ocurre con el Ministro de Transportes y Telecomunicaciones ${ }^{26}$ y la figura del Director Regional del Servicio de Impuestos Internos ${ }^{27}$ y la Junta General de

\footnotetext{
${ }^{25} \mathrm{El}$ artículo $5^{\circ}$ del Código Orgánico de Tribunales establece cuáles son los únicos tribunales que forman parte del Poder Judicial: "Integran el Poder Judicial, como tribunales ordinarios de justicia, la Corte Suprema, las Cortes de Apelaciones, los Presidentes y Ministros de Corte, los tribunales de juicio oral en lo penal, los juzgados de letras y los juzgados de garantía. Forman parte del Poder Judicial, como tribunales especiales, los juzgados de familia, los Juzgados de Letras del Trabajo, los Juzgados de Cobranza Laboral y Previsional y los Tribunales Militares en tiempo de paz".

${ }^{26}$ Según el Tribunal Constitucional (sentencia rol no 176 - 1993) el Ministro de Transportes y Telecomunicaciones cuando resuelve sobre una oposición a un otorgamiento o modificación de una concesión en las áreas de su competencia actúa como un tribunal especial situado fuera del Poder Judicial.

27 El Tribunal Constitucional salvó la constitucionalidad de este organismo administrativo para ejercer funciones jurisdiccionales sosteniendo que es un tribunal especial que ejerce por lo tanto legítimamente jurisdicción. Sentencia rol no 616 - 2006, de fecha 6 de septiembre de 2007. En otros trabajos he expresado mi parecer opuesto al criterio sustentado por el Tribunal Constitucional en el sentido que este organismo no es un tribunal de justicia y no ejerce por tanto legítimamente jurisdicción. BORDALÍ (2005) pp. 356 y ss.; BORDALí (2006) pp. 31 y ss.
} 
Aduanas $^{28}$ que prontamente dejarán de ejercer estas funciones jurisdiccionales. Pero además algunos autores ${ }^{29}$ sostendrán que cada Superintendencia (de Bancos e Instituciones Financieras; de Valores y Seguros; de Administradoras de Fondos de Pensiones, de Seguridad Social; de Electricidad y Combustibles; de Servicios Sanitarios y de Salud) cuando sancionan o dictan actos que perjudiquen a los entes controlados actúan como tribunales de justicia o como órganos que ejercen jurisdicción. Luego está la situación del Senado como tribunal que conoce de las acusaciones políticas (art. 53 no 1 CPR).

Y cuando se dice que hay tribunales que están dentro y otros fuera del Poder Judicial, se apunta a que los primeros están regulados por un mismo estatuto orgánico que en este caso es la conjunción de los preceptos del Capítulo VI de la Constitución Política de la República y el Código Orgánico de Tribunales. El resto de los tribunales tendrán el estatuto orgánico particular que la ley haya dispuesto rigiendo en algunos casos, supletoriamente, dicho Código Orgánico de Tribunales. ¿Y qué diferencia puede haber entre el estatuto orgánico constitucional y del Código Orgánico de Tribunales y los estatutos orgánicos especiales del resto de los tribunales? La respuesta es que en el Código Orgánico de Tribunales se consagran de manera más exhaustiva las prohibiciones a que están sujetos los jueces; las causales que hacen presumir su falta de imparcialidad; las obligaciones que tienen; la garantía de la inamovilidad y a su vez la remoción legítima de los jueces; los distintos tipos de responsabilidad, etcétera, lo que en principio permite asegurar de mejor modo la independencia externa de los jueces para un imparcial ejercicio de la función judicial.

Si se mira al nombramiento de los jueces que pertenecen al Poder Judicial, veremos que todos ellos son nombrados conjuntamente entre la decisión del Presidente de la República y un Tribunal Superior de Justicia, sea Corte Suprema o Corte de Apelaciones. En el caso de los ministros de la Corte Suprema además requieren de la aprobación del Senado (art. 78 CPR). Si observamos la situación de algunos tribunales situados fuera del Poder Judicial veremos que el sistema de nombramiento es altamente variado.

Tomemos solo algunos ejemplos. En relación a los integrantes del Tribunal de Defensa de la Libre Competencia, del DL 211, veremos que uno de ellos debe ser abogado y lo designará el Presidente de la República de una quina que por concurso

\footnotetext{
${ }^{28}$ El Tribunal Constitucional ha declarado la naturaleza jurisdiccional de este organismo administrativo en el desarrollo de esta función en la sentencia rol no 247 - 1996.

29 Enrique Evans sostiene que "el administrador está ejerciendo una función jurisdiccional cuando, por ejemplo, impone sanciones, priva de la administración de bienes a sus dueños, temporal o definitivamente, desconoce el derecho de asociación negando arbitrariamente la personalidad jurídica, etc. Y el reclamo ante la justicia ordinaria no es más que la continuación de ese proceso jurisdiccional ante un órgano de superior jerarquía. Sostener, por tanto, que 'lo jurisdiccional' se inicia con la intervención del tribunal ordinario y negar que las autoridades políticas y administrativas son 'órganos que ejercen jurisdicción' cuando afectan derechos de las personas, es un grave error que desconoce la letra, el espíritu y la historia del precepto que nos ocupa [Art. 19 no 3 CPR]". Evans (2004) p. 144. Natalia Muñoz, a propósito de las actuaciones de las superintendencias de la Administración del Estado, sostiene que para "gran parte de los autores nacionales la etapa en sede administrativa no constituye fase jurisdiccional, la que comenzaría recién cuando se presenta la reclamación ante la corte de apelaciones respectiva o ante otro tribunal perteneciente al Poder Judicial", tesis que se opone a la de Enrique Evans. MuÑoz (2007) p. 899.
} 
público deberá efectuar la Corte Suprema. El resto de los integrantes (cuatro profesionales no abogados) serán designados por el Banco Central vía concurso público (dos de ellos) o bien por el Presidente de la República a propuesta del Banco Central (los otros dos).

Los miembros de los Tribunales Tributarios y Aduaneros serán nombrados por el Presidente de la República de una terna efectuada por la Corte de Apelaciones de Santiago de unos miembros que figuran en una lista realizada por el Consejo de Alta Dirección Pública, órgano que el Tribunal Constitucional lo ha definido como servicio público descentralizado que integra la Administración del Estado ${ }^{30}$.

Los miembros del Tribunal de la Contratación Pública serán designados por el Presidente de la República de una terna propuesta por la Corte Suprema que a su vez recibirá una lista del concurso público que al efecto llevará a cabo la Corte de Apelaciones de Santiago.

Los jueces de Policía Local son designados por la Municipalidad respectiva de una terna propuesta por la Corte de Apelaciones en concurso público de antecedentes.

Los miembros del Panel de Expertos de la Ley General de Servicios Eléctricos son designados por el Tribunal de Defensa de la Libre Competencia previo concurso público de antecedentes. El Ministro de Economía, Fomento y Reconstrucción dicta una resolución donde formaliza el nombramiento.

Vemos de este modo que el sistema de nombramiento de los jueces chilenos es bastante complejo y disímil, aunque en ningún caso se utilice la designación de los jueces por un solo poder estatal que pudiera condicionar la independencia futura de esos jueces. En este sentido la crítica al modelo orgánico judicial existente en nuestro país no puede dirigirse necesariamente hacia poner en tela de juicio la dependencia de los jueces hacia los poderes políticos sino antes bien hacia la dispersión y complejidad orgánica.

En este punto conviene preguntarse si el fin buscado por el constituyente de 1980 de regular un Poder Judicial se cumple realmente. Si analizamos el artículo 77 CPR en la parte que prescribe que "Una ley orgánica constitucional determinará la organización y atribuciones de los tribunales que fueren necesarios para la pronta y cumplida administración de justicia en todo el territorio de la República”, es legítimo preguntarse si el fin de garantía de esa disposición se cumple satisfactoriamente. En este sentido esa disposición puede ser interpretada no solo como exigencia de una determinada jerarquía de la ley que debe regular la organización de los tribunales de justicia que desarrollarán la función judicial en causas civiles y criminales, sino que también puede ser interpretada en un sentido de búsqueda de unidad y homogeneidad en la regulación orgánica de los tribunales de justicia. Y no solo de los que forman el Poder Judicial, sino de todos los tribunales. En este sentido la disposición podría ser interpretada en un deseo de regular en un solo cuerpo legal a todos los tribunales de justicia del país. Obviamente la unidad no es un valor en sí mismo, sino que lo que se buscaría con esta interpretación es que todos los tribunales tengan una misma organi-

30 STC rol no 1243 - 2008 de fecha 30 de diciembre de 2008. 
zación en pro de la igualdad y libertad de los ciudadanos, principio organizativo liberal típicamente del Estado de Derecho ${ }^{31}$.

Más dudoso se plantea el problema de la duración de los jueces en sus cargos. Siguiendo una tradición que se remonta al derecho inglés en la Act of Settlement, de 1701, en que los jueces son nominados de por vida bajo la cláusula during good behaviour o quamdiu se bene gesserint, garantía esencial para la independencia judicial ${ }^{32}$, la Constitución de 1980 y el Código Orgánico de Tribunales reconocen relativamente este principio. En efecto, el artículo $80 \mathrm{CPR}$ señala que "los jueces permanecerán en sus cargos durante su buen comportamiento; pero los inferiores desempeñarán su respectiva judicatura por el tiempo que determinen las leyes”. Es del caso señalar que el Código Orgánico de Tribunales no establece plazo de duración para los jueces inferiores. Estos, mientras tengan el deseo, salud de desempeñar el cargo y buena conducta, permanecen en el cargo. Sin embargo, como veremos, las leyes que regulan a los tribunales especiales que estamos examinando ejemplarmente, en algunos de esos casos establecen una duración temporal en el cargo.

En efecto, los jueces del Tribunal de Defensa de la Libre competencia duran seis años en sus cargos, pudiendo ser designados por nuevos períodos. Los jueces de los Tribunales Tributarios y Aduaneros no tienen plazo de permanencia en sus cargos. Sí lo tienen los jueces del Tribunal de la Contratación Pública que duran cinco años en sus cargos pudiendo ser nuevamente designados. Permanentes son también los jueces de policía local. Pero nuevamente a plazo fijo son los miembros del Panel de Expertos que duran seis años en sus cargos pudiendo ser reelegidos.

El ejercicio de la jurisdicción en forma permanente, que implica estabilidad en el empleo con toda su significación económica que ello envuelve, puede ser entendido como una más de las garantías que permiten un ejercicio imparcial de la función jurisdiccional. Si quien juzga, mientras mantenga un buen comportamiento, tiene la certeza que podrá desempeñar su labor con una justa retribución por toda su vida hasta cumplir los 75 años de edad (art. 80 inciso $2^{\circ} \mathrm{CPR}$ ), puede sentirse libre para aplicar la ley y solo la ley a los casos sometidos a su decisión, sin necesidad de preguntarse cómo vivirá el día de mañana, lo que podría hacerlo inclinar hacia una de las partes en conflicto (sea un órgano estatal o un particular), quien, terminado su mandato, podría ofrecerle trabajo o dinero. La permanencia indefinida en los cargos, mientras mantengan una buena conducta y hasta cierta edad, es una importante herramienta institucional para asegurar la independencia de los jueces.

Luego está el tema de las responsabilidades e incompatibilidades que afectan a los jueces integrantes del Poder Judicial y que regula el Código Orgánico de Tribunales. Los jueces integrantes del Poder Judicial tienen un complejo sistema de responsabilidades que van desde la penal, la civil y la disciplinaria, hasta la política en el caso de los ministros de los Tribunales Superiores de justicia. El tema es determinar si esas responsabilidades (con exclusión de la política) se aplican a los tribunales situados fuera del

\footnotetext{
31 De OTTO (1989) p. 151.

32 GUARNIERI (1981) p. 148.
} 
Poder Judicial. Si las respectivas leyes que regulan a esos tribunales nada dicen, se puede entender que la responsabilidad disciplinaria procede siempre por aplicación del artículo $82 \mathrm{CPR}$ que reconoce a la Corte Suprema la superintendencia directiva, correccional y económica de todos los tribunales de la Nación, con las excepciones que ese mismo precepto establece: Tribunal Constitucional, Tribunal Calificador de Elecciones y los tribunales electorales regionales. En algunos de los casos examinados se dice expresamente por la ley que están sometidos a la supervigilancia de las Cortes de Apelaciones y Corte Suprema como ocurre con los jueces de policía local y los jueces de la contratación pública. En los otros nada se dice por el legislador.

Sobre la responsabilidad civil de los jueces se podría llegar siempre a ella aplicando las reglas generales de la responsabilidad extracontractual que regula el Código Civil $^{33}$. La responsabilidad penal es más discutible en el sistema legislativo chileno. ¿Necesita el cuerpo legislativo que regula a esos jueces reconocerla expresamente? Según Pereira, ella abarca a todos los jueces, "sin excepción" 34 . En relación al específico delito de prevaricación y prevaricación-cohecho que regula el artículo 223 del Código Penal, este se aplica a "los miembros de los tribunales de justicia colegiados o unipersonales y los fiscales judiciales", lo que Politoff, Matus y Ramírez entienden de manera amplia comprendiendo "los tribunales ordinarios y especiales (jueces del trabajo, militares, de aduana, etc.)"35. De los ejemplos aportados por estos autores se colige que la responsabilidad penal judicial es aplicable a todo juez de un tribunal de justicia, ordinario o especial y en este último caso integrante o no del Poder Judicial ${ }^{36}$. El problema se presenta con la variabilidad con que el legislador aborda este tema. En efecto, tratándose de los tribunales especiales que estamos analizando en estas líneas solo respecto de los miembros de los Tribunales Tributarios y Aduaneros se señala expresamente que tienen responsabilidad penal (art. $8^{\circ}$ Ley 20.322). En los otros casos no se dice nada. ¿Cómo tomar ese distinto tratamiento? Para entender que no se aplica la responsabilidad penal debería haber al menos una norma legal que expresamente no haga aplicable esa responsabilidad penal, como ocurre con los ministros de la Corte Suprema por disposición del artículo $324 \mathrm{COT}^{37}$. Por lo tanto la referencia de la procedencia de la responsabilidad penal que se hace respecto de algunos jueces especiales, como sucede con los jueces tributarios y aduaneros, no aporta nada al Código Penal. Solo introduce confusión a esta inorgánica regulación de la judicatura chilena.

\footnotetext{
33 En igual sentido, PEREIRA (1996) p. 268.

34 Pereira (1996) p. 268.

35 Politoff, Matus y Ramírez (2004) p. 506

36 Sin perjuicio que además respondan penalmente aquellas personas que por ministerio de la ley desempeñen los cargos de miembros de los tribunales de justicia colegiados o unipersonales (art. 227 1. CP), entre los que cabe incluir a abogados integrantes y alcaldes que actúan como jueces de policía local. POLITOFF, MATUS y RAMÍREZ (2004) p. 506.

37 A pesar que hay doctrina que señala que el art. 324 COT que exime de responsabilidad penal a los ministros de la Corte Suprema se encuentra derogado tácitamente por el artículo 76 inc. 2o CPR (actual 79 inc. 2o CPR). PEREIRA (1996) p. 267; otros sostienen la inconstitucionalidad del referido artículo 324 COT en esta materia. CABALlero (2005) p. 166.
} 
Luego está el tema de las incompatibilidades que afectan a los jueces del Poder Judicial. Una de esas incompatibilidades dice relación con el ejercicio de la abogacía. Parece ser que a los únicos jueces de estos tribunales especiales que estamos analizando que se les aplica el mismo régimen de incompatibilidades que a los pertenecientes al Poder Judicial son a los jueces de los Tribunales Tributarios y Aduaneros. El resto de los jueces examinados puede por lo tanto ejercer sin limitación alguna la profesión de abogado.

Podemos concluir entonces que el caso chileno destaca por un elevado nivel de fragmentación en la organización judicial, con tribunales que pertenecen a la organización Poder Judicial y otros que no forman parte de ella, y con algunos tribunales no independientes de los poderes políticos activos. En algunos casos estamos frente a tribunales que en su regulación esencial no tienen independencia respecto de los poderes políticos (caso del Ministro de Transportes y Telecomunicaciones). En otros casos se trata de tribunales en lo esencial independientes (nombramiento de sus integrantes entre distintos poderes y garantía de la inamovilidad), pero que por sus regulaciones orgánicas particulares se pone en tela de juicio esa independencia, como ocurre con el caso de nombramiento de los jueces a plazo fijo. Y más allá de la crítica por falta de un diseño institucional que garantice la independencia de los jueces, se puede avanzar una crítica que atraviesa a todo el sistema judicial chileno que apunta hacia una dispersión normativa que no asegura siempre y en todo lugar la igualdad de tratamiento de los justiciables, además de propender a la inseguridad jurídica.

A continuación analizaremos el caso chileno en contraste con algunas democracias europeas -Italia y España-, y luego el caso de los Estados Unidos de Norteamérica.

\section{MAYOR REALIZACIÓN RELATIVA DE LOS PRINCIPIOS DE UNIDAD Y EXCLUSIVIDAD JUDICIAL EN ITALIA QUE EN CHILE \\ La Constitución italiana de 1947 (en adelante Ci), al contrario de la chilena de} 1980, tiene una especial preocupación por la unidad y exclusividad en el ejercicio de la jurisdicción a los fines de lograr una autonomía de esta y, si se quiere, posibilitar la independencia individual de cada juez y tribunal para, a su vez, realizar el fin último de aplicación imparcial e irrevocable de la ley al caso concreto. En efecto, el artículo $102 \mathrm{Ci}$ dispone que la función jurisdiccional se ejerce por magistrados ordinarios, agregando su inciso segundo que no pueden ser instituidos jueces extraordinarios o jueces especiales, pudiendo solamente instituirse, junto a los órganos judiciales ordinarios, secciones especializadas para determinadas materias, así como también la participación de ciudadanos extraños a la magistratura.

Pero el sistema constitucional italiano permite la existencia de tribunales especiales: se trata de los que la propia Constitución reconoce y ellos son la Corte Constitucional; los órganos de la justicia administrativa (Consejo de Estado y Tribunales Administrativos Regionales); la Corte de las Cuentas y los tribunales militares, a los que algunos agregan la Sección disciplinaria del Consejo Superior de la Magistratura, pero que la Constitución italiana no califica como jurisdiccional ${ }^{38}$.

38 GUastini y Pizzorusso (1994) p. 212. 
Por otro lado están los tribunales especiales que existían al promulgarse la Constitución de 1947, ya que la previsión de la Constitución italiana es que prohíbe la constitución de nuevos tribunales especiales pero no necesariamente los que existían al momento de la promulgación del texto constitucional. En este último caso se debe tener presente la cláusula general incluida en la VI disposición transitoria que prevé la "revisión” de tales órganos. Algunos de ellos fueron declarados inconstitucionales por la Corte Constitucional pero no por este proceso de "revisión" sino por considerar que respecto de ellos faltaba el requisito esencial de todo juez o tribunal, como lo es la independencia respecto de los poderes políticos. Fueron los casos del "Ministro-juez"39; el intendente de Finanzas y el Presidente del Consorcio Autónomo para el puerto de Génova. En otros casos como las comisiones tributarias la Corte Constitucional dictó una sentencia interpretativa que excluyó el carácter jurisdiccional de algunas de sus funciones ${ }^{40}$.

Entre los tribunales especiales que quedaron con competencia en Italia están los casos de los tribunales regionales de aguas públicas (aunque algunos los consideran secciones especializadas de las Cortes de Apelaciones) y los comisarios regionales liquidadores de usos cívicos ${ }^{41}$, entre los más destacados.

Pero no se puede decir que el elenco de tribunales termina en Italia aquí. Existen muchas dudas de cómo calificar a las autoridades administrativas independientes que en muchos casos ejercitan funciones judiciales y bajo la forma de todo tribunal de justicia (con contradictorio entre partes, discusión oral, motivación de las decisiones, etcétera). Estas autoridades se encuentran separadas del Ejecutivo conservando una naturaleza formalmente administrativa pero desarrollando un rol de tipo judicial o parajudicial. Se trata de órganos que no pertenecen formalmente al Ejecutivo, al Legislativo y ni al Judicial, pero que desarrollan funciones propias de esos tres clásicos poderes.

Una de esas autoridades italianas es el Garante de la Privacy que entre otras competencias dirime las controversias entre quien reclama la lesión de su derecho a la privacidad y la empresa que ha constituido una base de datos informatizada, es decir, actúa esta autoridad supra partes, como todo juez o árbitro. Sin embargo, la Corte de Casación italiana, secciones unidas, en sentencia de 23 de mayo de 2002, no 7341, le ha negado a esta autoridad independiente una naturaleza de órgano jurisdiccional en sentido propio $^{42}$. Se ha hablado que estos órganos (como también la Autoridad antitrust) desarrollan una función parajurisdiccional ${ }^{43}$.

${ }^{39}$ Como sostiene Virgilio Andrioli, en algunos casos de estos órganos administrativos que ejercían funciones jurisdiccionales, el problema no es tanto su falta de independencia sino que su figura se pone en una antinomia con el bien más antiguo y radical principio que consiste en el nemo iudex in causa propia. Así, en el caso del Ministro-juez, este no puede ser juez por el simple pero insuperable motivo que, siendo el jefe de la Administración, y existiendo un órgano directo o bien funcionalmente desconcentrado de esa Administración que es parte del denominado juicio, no puede el Ministro estar en una posición de supra partes en dicha causa. ANDRIOLI (1992) p. 537.

40 GuAstini y Pizzorusso (1994) pp. 213 y 214.

41 Mandrioli (2000) p. 122.

42 Clarich (2005) p. 47.

43 Clarich (2005) p. 152. 
No se trata en este caso de autoridades que pertenecen a la Administración, como era el caso del Ministro-juez, sino de órganos que deciden como terceros y bajo el principio de legalidad y no bajo las órdenes del Ejecutivo. Es que si estuvieran ligados jerárquicamente al Gobierno o a la Administración ya se habría declarado, probablemente, su inconstitucionalidad por la Corte Constitucional italiana.

Ahora bien, la Corte Constitucional italiana dictó en sus días una sentencia que establece lo que se ha de entender por juez para efectos de lo que dispone el artículo 101 $\mathrm{Ci}$, que expresa en su inciso segundo que "los jueces están sujetos solo a la ley". Se ha entendido que la expresión juez es sinónima de "autoridad jurisdiccional”. Así en el fallo 83/1966, la Corte señaló que se debe considerar "autoridad jurisdiccional” también a los órganos que aunque extraños a la organización de la jurisdicción e institucionalmente establecidos para cumplir tareas de otra naturaleza, estén investidos, auque sea de un modo excepcional, de funciones juzgadoras para la objetiva aplicación de la ley, teniendo siempre la posición de supra partes, como tercero que decide imparcialmente. La Corte Constitucional italiana, de este modo, ha señalado que es posible que otros órganos distintos de los tribunales de justicia propiamente tales ejerzan jurisdicción, pero a condición de que no estén ligados por vínculos de sujeción formales o sustanciales respecto de autoridades administrativas o políticas. Deben asimismo gozar de la garantía de la inamovilidad ${ }^{44}$.

El caso italiano en esta última parte se asemeja a lo que sucede en Chile con la denominación “órgano que ejerce jurisdicción”, aunque, como veremos, con una diferencia esencial.

En Chile, a propósito de la expresión “órgano que ejerce jurisdicción” que reconoce el artículo 19 no 3 inc. $5^{\circ} \mathrm{CPR}$, el Tribunal Constitucional chileno ${ }^{45}$ ha señalado que la función jurisdiccional es genérica y omnicomprensiva respecto de todos aquellos órganos que resuelven conflictos que afectan bienes y derechos de las personas, aunque no sean propiamente "tribunales" e incluso no formen parte del Poder Judicial, sin perjuicio de que en definitiva se encuentren siempre sujetos a la superintendencia disciplinaria de la Corte Suprema (Considerando Décimo Séptimo). Luego agrega que [...] de suerte tal que no solo los tribunales, propiamente tales, formen o no parte del Poder Judicial, ejercen jurisdicción sino que también lo hacen otros órganos, como algunos que incluso integran la Administración del Estado, al resolver situaciones que afecten a las personas y sus bienes. Entre dichos órganos ciertamente se encuentra el Servicio de Impuestos Internos, particularmente sus Directores Regionales, al resolver las reclamaciones tributarias, a que aluden los artículos 115 y siguientes del Código Tributario, a cuya actuación jurisdiccional también se le aplican los principios del debido proceso, como se explicará más adelante (Considerando Décimo Octavo).

La diferencia esencial entre los criterios sustentados en el derecho italiano y el chileno para entender qué es un "órgano que ejerce jurisdicción”, estriba en que para la Corte Constitucional italiana es lícito, por así decirlo, que órganos que no son propia-

\footnotetext{
${ }^{44}$ Guastini y Pizzorusso (1994) p. 216.

45 Sentencia del Tribunal Constitucional rol no 616 - 2006, de fecha 6 de septiembre de 2007.
} 
mente tribunales, como podrían ser los de carácter administrativo, ejerzan jurisdicción, siempre y cuando se pueda predicar respecto de ellos la garantía de la imparcialidad que debe estar presente en toda actividad jurisdiccional, lo que se logra regulando ese ejercicio jurisdiccional en cabeza de un órgano independiente de los poderes administrativos o políticos y respecto del cual esté garantizada plenamente la inamovilidad.

Nada de eso está presente en la doctrina y jurisprudencia chilenas ${ }^{46}$. En concreto, para nuestro Tribunal Constitucional las garantías de tipo orgánico nada inciden en la calificación de la función jurisdiccional. Basta con el poder atribuido por ley a un órgano para resolver una litis, así como el desarrollo del proceso, para que estemos en presencia de un órgano que ejerce la función jurisdiccional. Pero, como señaló en sus días Virgilio Andrioli en Italia con razón, la observancia de las reglas del juego procesal no bastan para transformar a una autoridad administrativa o política en un juez imparcial, pero sí se puede hacer de un juez constitucionalmente ilegítimo un administrador constitucionalmente válido ${ }^{47}$. Esto tiene importancia para la pretensión de la ley chilena de hacer de los órganos administrativos o políticos órganos jurisdiccionales, auque decidan los asuntos que la ley les encomienda no como terceros supra partes sino como partes interesadas. Se rompe así con el mandato constitucional que prohíbe al Presidente de la República y al Congreso Nacional ejercer funciones judiciales (art. 76 CPR) y, lo que a mi juicio es más importante aún, se afecta el derecho fundamental de los justiciables a ser enjuiciados por un tribunal independiente e imparcial ${ }^{48}$. No basta de este modo asegurar un debido proceso en cuanto garantía de un contradictorio y derecho de defensa; falta asegurar un debido proceso como garantía orgánica de independencia e imparcialidad.

Se podría objetar mi afirmación señalando que no hay problema alguno en permitir a un órgano político ejercer jurisdicción en la medida que lo que decida sea revisable ante la judicatura. Es decir, sería válido atribuir la primera respuesta al ciudadano a un órgano no independiente de los poderes políticos siempre y cuando exista una especie de segunda instancia ante la judicatura. Frente a tal argumento señalaré que no se ajusta a las garantías de un debido proceso que a los justiciables se les prive de una primera instancia ante un verdadero tribunal de justicia.

Esos órganos políticos no pueden ser considerados jurisdiccionales al tenor de lo dispuesto por el artículo $76 \mathrm{CPR}$, pero nada obsta que dentro de las funciones administrativas que la Constitución o las leyes les encomiendan, estén las de resolver asuntos

\footnotetext{
46 Para un desarrollo más específico de este asunto remito a BORDALí (2007a) pp. 509-528; BordALí (2008), pp. 185-219.

47 ANDRIOLI (1992) p. 554. Una tesis similar ha sostenido el ex Ministro del Tribunal Constitucional chileno Jorge Correa Sutil en el voto de minoría del fallo del Tribunal Constitucional rol no 499-2006, sobre recurso de inaplicabilidad del (ahora derogado) artículo 116 del Código Tributario interpuesto por la Compañía Sudamericana de Vapores. En dicho voto llegaba a la conclusión que el Director Regional del Servicio de Impuestos Internos no desarrollaba una función jurisdiccional legítima, es decir, coherente con las disposiciones constitucionales. Pero da a entender el voto de minoría que ese Director desarrollaba una función administrativa que al parecer era coherente con la Constitución.

${ }^{48}$ Para una justificación de estos extremos véase BORDALí (2007a) pp. 523 y ss.
} 
que afectan los derechos o intereses de los ciudadanos. En ello no hay problema alguno siempre que se entienda que esa decisión puede ser revisada posteriormente por un órgano jurisdiccional como tribunal de primera instancia, cuya decisión, a su vez, podría ser controlada por otro tribunal ya por vía de apelación o nulidad.

Volviendo al derecho italiano, hay que señalar que donde se produce una mayor dispersión del poder judicial en Italia es en relación con el gobierno judicial, donde junto al Consejo Superior de la Magistratura que prevé el artículo 104 y siguientes de la Constitución, el legislador ha creado el Consejo de Presidencia de la Magistratura Administrativa, el Consejo de Presidencia de la Corte de las Cuentas, el Consejo de Presidencia de la Justicia Tributaria y el Consejo de la Magistratura Militar. El problema de esta situación, a juicio de Guastini y Pizzorusso ${ }^{49}$, es que no hay ninguna vinculación entre tales colegios produciéndose una desarticulación del "poder judicial" italiano.

En definitiva, el derecho italiano garantiza de mejor forma que el chileno la imparcialidad de los jueces, toda vez que no admite que órganos que pertenecen a los poderes políticos activos ejerzan jurisdicción. Italia combina adecuadamente el recurso a los tribunales independientes que caracterizan a la mayoría de los Estados europeos contemporáneos, tribunales que conocen del contencioso civil, penal, administrativo o constitucional, con el uso de las agencias administrativas autónomas propias de los países anglosajones. En ambos casos se garantiza institucionalmente la independencia de los juzgadores para una imparcial aplicación de la ley. En relación al gobierno judicial, Italia presenta más fragmentación que el chileno ya que frente a un único gobierno judicial ejercido en Chile por la Corte Suprema, allá hay cinco diferentes gobiernos judiciales, según el tipo de tribunales de que se trate. Pero esa mayor fragmentación del Poder Judicial italiano no es capaz de poner en jaque el fin esencial que define a la jurisdicción, cual es un diseño institucional que permita presumir razonablemente la imparcial aplicación de la ley en el caso concreto.

\section{ESPAÑA O UN EJEMPLO PARADIGMÁTICO EN EL RECONOCIMIENTO DE LOS PRINCIPIOS DE UNIDAD Y EXCLUSIVIDAD JUDICIAL}

En la Constitución española de 1978 (en adelante Ce) hay una casi perfecta relación entre Poder Judicial y actividad jurisdiccional, respetándose así los principios de unidad y exclusividad judicial. Esa situación contrasta con la situación chilena donde vimos que la mayoría de los tribunales que ejercen jurisdicción se sitúan fuera de la estructura denominada Poder Judicial.

Es casi perfecta la situación española porque solo no integran el Poder Judicial, pese a que inequívocamente ejercen jurisdicción ${ }^{50}$, el Tribunal Constitucional y el Tribunal de Cuentas ${ }^{51}$. Al margen de estas dos excepciones que prevé la Constitución españo-

\footnotetext{
49 GUASTINI y Pizzorusso (1994) 197.

${ }^{50}$ REQUEJO (1989) p. 155.

${ }^{51}$ Situación aparte es la que se da con la denominada jurisdicción militar que se la ha entendido como una jurisdicción especial situada fuera del Poder Judicial, pero no expresamente aludida por la Constitución. De OтTо (1989) pp. 55-57.
} 
la solo cabe ejercer jurisdicción a partir de la previa integración en el denominado Poder Judicial. Por ello, a juicio de algunos autores la expresión Poder Judicial en España es sinónima de Organización Judicial o de Conjunto de Juzgados y Tribunales ${ }^{52}$.

En el derecho español tienen mucha relevancia los principios de unidad y exclusividad jurisdiccional. Solo hay un Poder Judicial legítimo en el Estado de Derecho y ese Poder Judicial solo puede estar integrado por un único conjunto de personas caracterizado por gozar de independencia y estar sometidos íntegramente a la ley y al Derecho, así como por tener otras garantías relacionadas con estas (la inamovilidad, la responsabilidad, por completar el dictado del artículo 117 . 1 Ce). Pero la unidad por sí sola no basta. Se requiere además que el poder de administrar justicia le sea atribuido en exclusiva a esa única jurisdicción y a ese único conjunto de personas ${ }^{53}$. "La garantía de independencia, imparcialidad y sumisión a la ley y al Derecho que conlleva la unidad de jurisdicción, se perdería si la potestad de administrar justicia pudiera confiarse a otras personas, a otros conjuntos de personas, o a otros poderes distintos de los agrupados bajo dicho principio, es decir, si no tuvieran esa potestad atribuida en exclusiva" 54 .

La exclusividad, ha indicado Francisco José Hernando ${ }^{55}$, entronca directamente con el derecho fundamental de los ciudadanos de acceso a los órganos jurisdiccionales y con la prohibición de la justicia privada como forma de resolución de conflictos jurídicos.

Los principios de unidad y exclusividad jurisdiccional parecen ser una conquista tardía del sistema constitucional español o una reconquista de lo que se pretendió con la Constitución liberal de Cádiz. A principios del siglo XX se hablaba en España de una vía "Jurisdiccional administrativa" o del desempeño por la Administración de una "cierta función judicial" 56 , lo que resulta claramente incompatible con las disposiciones de la Constitución de 1978, pues lo esencial en el ordenamiento judicial español es la independencia de los tribunales de justicia. "Podemos afirmar tajantemente, sin ninguna ambigüedad, que la Constitución española de 1978, considera la independencia del juez, la independencia de los tribunales de justicia, como un valor fundamental al mismo orden jurídico-político del Estado; considera la independencia de los tribunales como el principio que permite descubrir la Justicia en la organización del Estado; valor que se erige en pieza esencial para consolidar un Estado de Derecho que asegure el imperio de la ley como expresión de la voluntad popular, en palabras del preámbulo de la Constitución" 57.

Esto quiere decir que en España es inadmisible que se atribuya el ejercicio de la jurisdicción a otras autoridades públicas distintas de los jueces y magistrados del Poder Judicial, sea que esas autoridades se enclaven en el Poder Legislativo o en el Ejecutivo. Eso violaría claramente el principio de unidad jurisdiccional. Hay una estrecha relación

\footnotetext{
52 HERNANDO (2003) p. 21.

53 Moreno Catena (2005) p. 62.

${ }^{54}$ Moreno Catena (2005) p. 63.

55 HeRnANDO (2003) p. 26.

56 PEDRAZ (1993) p. 194.

57 BANDRÉS (1987) p. 25
} 
entre el principio de unidad y exclusividad jurisdiccional y la propia organización de los juzgados y tribunales, así como la independencia judicial. Es que de nada serviría proclamar solemnemente en la Constitución la independencia del juez y el ejercicio exclusivo de la potestad jurisdiccional para más tarde violar este principio sustrayendo competencias a los tribunales ordinarios de justicia, acudiendo al recurso de crear ciertos órganos especializados de apariencia judicial radicados en la Administración ${ }^{58}$. Ese sería por ejemplo el caso del Ministro de Transportes y Telecomunicaciones y el del Director Regional de Servicio de Impuestos Internos chilenos.

En España, los asuntos judiciales en los que figura comprometida la Administración del Estado son conocidos por los tribunales con competencia contencioso-administrativa como lo son los juzgados de lo contencioso-administrativo, las salas de lo contencioso-administrativo de los Tribunales Superiores de Justicia de las Comunidades Autónomas y luego las salas de lo contencioso-administrativo de la Audiencia Nacional y del Tribunal Supremo, respectivamente. Se trata en todos esos casos de tribunales ordinarios integrantes del Poder Judicial español.

Lo anterior quiere decir que la figura de agentes administrativos ejerciendo jurisdicción está absolutamente prohibida en el derecho español. Ni siquiera se permite el ejercicio de la jurisdicción a los agentes administrativos autónomos o independientes que regula el derecho español. Por ello podemos decir que el sistema español se encuentra en las antípodas del chileno. No solo no considera jurisdiccional a la actividad de la Administración del Estado que es capaz de afectar o determinar los derechos de las personas, sino que ni siquiera tolera que entes que tienen neutralidad respecto de los poderes políticos activos, como es el modelo de las agencias autónomas, ejerzan jurisdicción.

En definitiva, todos los tribunales españoles, a excepción del Tribunal Constitucional y el Tribunal de Cuentas, integran el Poder Judicial español; se encuentran sometidos al gobierno del Consejo General del Poder Judicial y se rigen por un mismo estatuto orgánico que garantiza la independencia, inamovilidad y responsabilidad de los jueces y magistrados que los integran.

La unidad del Poder Judicial español tiene un valor destacable en el sentido que todos los tribunales de justicia aparecen regulados por un estatuto orgánico que se encarga de asegurar la independencia para un imparcial ejercicio de la función jurisdiccional. En ello radica lo valioso de la organización judicial española. Más allá de si pertenecen a no a una única estructura estatal -el Poder Judicial español-, lo que se debe resaltar es que a todos los jueces se les garantiza el ejercicio imparcial de sus tareas asignadas constitucionalmente, toda vez que los jueces son elegidos por el órgano de gobierno del Poder Judicial (el Consejo General de la Magistratura) y removidos solo por ese órgano. En definitiva, los jueces españoles están protegidos tanto en su nombramiento como en su remoción de las influencias de los órganos políticos activos ${ }^{59}$.

\footnotetext{
58 BANDRÉS (1987) pp. 19 y ss.

${ }^{59}$ No me haré cargo en esta sede de la discusión que ha existido en España y en otros países en el sentido de la influencia que los órganos políticos activos tienen en la designación de los miembros del Consejo General del Poder Judicial y que en algún sentido podría entenderse como una politización de la justicia. Dejaré por ahora constancia de que soy consciente de este problema.
} 


\section{ESTADOS UNIDOS DE NORTEAMÉRICA Y SU ESPECIAL ORGANIZACIÓN JUDICIAL}

La Constitución Federal de los Estados Unidos expresa una preocupación por la unidad y la independencia en el ejercicio de la jurisdicción cuando atribuye, en su artículo III, el poder judicial a una Corte Suprema y a los tribunales inferiores que el Congreso instituya, cuyos jueces gocen de las garantías de inamovilidad (life tenure) mientras dure su buen comportamiento y de un salario no sujeto a reducciones ${ }^{60}$. La unidad se refleja también en el plano del gobierno judicial, al estar sujeta la administración de todas las cortes federales a las directrices de la Conferencia Judicial, presidida por el Presidente de la Corte Suprema (Chief Justice). La Conferencia Judicial está integrada exclusivamente por jueces (el Presidente de la Corte Internacional de Comercio, los presidentes de las Cortes de Apelaciones de cada circuito y un juez de distrito por cada circuito judicial, elegidos por mayoría de votos de los jueces del mismo) y carece de atribuciones en los nombramientos judiciales. Sus facultades se refieren a la adecuada gestión administrativa de las cortes, a la recolección de información acerca del desempeño judicial y a la fiscalización, a través de comités ad hoc, de la buena conducta judicial a nivel federal (aunque sin potestad de ordenar la remoción de jueces federales) ${ }^{61}$.

Existe, sin embargo, al mismo tiempo, una larga práctica, respaldada (aunque no sin dificultades, según veremos) por una serie de precedentes, que acepta la atribución por el Congreso, en el ejercicio de sus competencias legislativas (de acuerdo al artículo I de la Constitución Federal), de la potestad para resolver controversias jurídicas y aplicar el derecho a casos particulares (adjudication), tanto a tribunales que no gozan de las garantías de independencia a las que se refiere el artículo III, como a agencias administrativas. Los primeros son conocidos como legislative courts, para distinguirlos de los constitucional courts, o cortes comprendidas en el artículo tercero de la Constitución Federal, y entre ellos se encuentran la United State Tax Court, la United State Court of Federal Claims, la United State Court of Military Appeals y las Bankruptcy Courts.

En cuanto a las administrative agencies, ellas comprenden, en un sentido muy amplio, acogido en la Administrative Procedure Act, a cualquier autoridad pública distinta del Congreso y los tribunales de justicia (constitucional y legislative courts) ${ }^{62}$. Ellas comprenden desde los Departments, que coadyuvan al Presidente en el ejercicio de sus funciones ejecutivas y corresponden a nuestros Ministerios, hasta las Independent Regulatory Commisions, conocidas también como agencias independientes y caracterizadas por su elevado grado de independencia respecto del control presidencial, dada la intervención del Senado en el

\footnotetext{
60 Actualmente el sistema judicial federal está constituido, junto a la Corte Suprema, por las cortes federales de apelación (apellate courts) y por las cortes federales de distrito (district courts), que son tribunales de primera instancia. El sistema federal coexiste además con los sistemas judiciales de cada Estado de la Unión, fundados en sus propias constituciones, que en general replican la estructura del sistema federal, atribuyendo el poder judicial a una corte suprema estatal, a las cortes de apelación y a las de primera instancia (trial courts of general jurisdiction), con diversas denominaciones. HAZARD y TARUFFO (1993) pp. 54 y ss.

${ }^{61}$ United State Code, Title 28, Section 331.

${ }^{62}$ MarchetTi (2005) pp. 23 y ss., FoX (2008) pp. 5-9.
} 
nombramiento de los commisioners y su inamovilidad por el período fijo de duración de su cargo $^{63}$. Entre esos extremos se sitúan las demás agencias -como las administraciones autónomas al interior de los Departaments ${ }^{64}$, o las Independent Executive Agencies ${ }^{65}$-, caracterizadas por grados variables de autonomía decisoria. Aunque las agencias administrativas suelen estar dotadas de potestades de creación de normas generales y abstractas (potestad de rulemaking), a muchas de ellas se atribuyen también potestades de adjudication, esto es, potestades para adoptar decisiones destinadas a producir efectos vinculantes (binding orders) respecto de uno o más sujetos determinados, que resultan afectados individualmente por ellas ${ }^{66}$. Dada la naturaleza vinculante e individual de esas decisiones, así como el que ellas impliquen, en muchos casos, dar solución a un conflicto entre sujetos privados o entre un sujeto privado y la agencia administrativa, esas potestades de adjudicación han sido consideradas como potestades de naturaleza al menos "quasi-judicial" 67.

La posición de las legislative courts y de las agencias administrativas dotadas de potestades de adjudicación en la arquitectura constitucional norteamericana ha suscitado discusiones en torno a la posible existencia de una delegación inconstitucional de poder judicial en tribunales que no cumplen con las garantías de independencia previstas en el mencionado artículo III. La cuestión ha sido abordada, con argumentos análogos respecto de ambas clases de órganos, en una serie oscilante de precedentes, que mantiene abierta la disputa doctrinal sobre la forma en que debieran ser interpretados y aplicados en el futuro ${ }^{68}$.

Tras una primera época de relativa calma, en que la Corte Suprema respaldó a través de diversas decisiones la atribución de poderes de adjudicación tanto a tribunales que no satisfacían los requerimientos del artículo III, como a agencias administrativas, el caso seminal, que reabre con intensidad la discusión en las últimas décadas, es Northern Pipeline Co. v. Maratón Pipeline Co. (458 U.S 50 1982) ${ }^{69}$. En esa decisión, relativa a

\footnotetext{
63 Son ejemplos de agencias independientes la National Labor Relations Board, la Federal Communication Commission, la Federal Trade Commission, o la Federal Energy Regulatory Comission. Sobre ellas véase también SCHWARTZ (1991) pp. 17 y ss.

${ }^{64}$ Como, por ejemplo, la Food and Drug Administration inserta en el Department of Health and Human Services, o el Animal and Plant Health Inspection Service, vinculada al Departamento de Agricultura.

65 Como la Environmental Protection Agency, por ejemplo.

66 MarchetTi (2005) p. 63.

67 PIERCE (2007) p. 116.

${ }^{68}$ Una síntesis crítica de esa discusión puede verse en FALlon (1988), BATOR (1990) y PFANDER (2004).

${ }^{69}$ La relativa calma de la primera época, que acomodó en el esquema constitucional a esas nuevas instituciones negando que estuvieran dotadas de "poder judicial", no implica que no se haya suscitado la cuestión de la existencia de límites a la competencia del Congreso para atribuir la potestades de adjudication sobre cualquier materia a tribunales fuera del artículo III. Dos sentencias significativas en ese sentido son Murray's Lessee $v$. Hoboken Lan \& Improvement Co. (59 U.S. [18 How.] 272 [1855], sobre tribunales legislativos, y Crowell $v$. Benson (285 U.S. 22 [1932]). Pfander (2004), pp. 733 y ss., PierCE (2007) pp. 117-118 y SCHWARTZ (1991) pp. 11-12. La primera desarrolla la tesis de la legitimidad de la atribución de competencia a tribunales no dotados de las garantías del artículo III tratándose de la resolución de controversias relativas a public rights; la considera que la atribución de potestades de adjudicación es compatible con la reserva del artículo 3, así como con la tutela del debido proceso, en la medida que se salvaguarde la posible revisión judicial de las cuestiones de hecho y de derecho establecidas en la decisión de la agencia, cuando se trate de casos que involucran derechos y responsabilidades privadas.
} 
una ampliación legislativa de las competencias de las bankruptcy courts, la decisión de mayoría consideró que el artículo III y el valor allí resguardado de la independencia judicial requerían una construcción restrictiva de las competencias del Congreso para crear tribunales al margen de esa disposición constitucional. El juez Brennan, autor de la opinión a la que concurrió con prevenciones la mayoría, intentó trazar esa frontera en la identificación de ciertos private rights -aquellos con un antecedente en el common lawcuya adjudicación es "esencialmente judicial" (inherently judicial) y solo puede ser resuelta, por tanto, por las cortes a las que se refiere el artículo III, únicos titulares del "poder judicial"70.

El criterio de decisión delineado en esa opinión dejaba al margen de la Constitución a buena parte de los tribunales y agencias administrativas con potestad de adjudicación creadas por el Congreso, pues la mayor parte de sus competencias tiene algún antecedentes en normas de common law previamente aplicadas por las cortes ${ }^{71}$. Paradójicamente, parece haber sido justamente la extendida valoración pragmática de las ventajas del sistema de decisión a través de tribunales y agencias especializadas sobre el sistema general de decisión a través del common law, la que determinó que ese test delineado en el caso Northern Pipeline no se impusiera en casos futuros. Así, en Thomas $v$. Union Carbide Agricultural Products Co. (473 U.S 568 [1985]), la mayoría no considera vinculante la opinión de Brennan y vuelve a una concepción amplia e inocua de los public rights cuya adjudicación por tribunales o agencias administrativas fuera del artículo III resulta constitucionalmente legítima. Según ella, cualquier disputa que recaiga sobre una materia que desde un punto de vista sustantivo pueda ser regulada por el Congreso puede ser resuelta por tribunales o agencias al margen del artículo III ${ }^{72}$.

Esta orientación complaciente ha sido confirmada en casos posteriores, en los que nuevamente se rechazó aplicar el test anunciado en Northern Pipeline. Así ocurrió, por ejemplo, en Commodity Futures Trading Comisión v. Schor (478 U.S. 835 [1986]), una decisión que da cuenta, con todo, de una variación de interés, en cuanto se rechaza en la justificación de la opinión de mayoría, el recurso a una interpretación del artículo III apoyada exclusivamente en categorías formales y se afirma la necesidad de atención a sus propósitos substantivos: "la protección del rol de un poder judicial independiente en el esquema constitucional" y "la salvaguardia del derecho de los litigantes a que sus causas sean resueltas por jueces libres de una potencial dominación por las otros poderes" 73 . Sobre esa base, la sentencia hace explícita la necesidad de una ponderación entre ese interés en la independencia judicial y el interés en la existencia de alternativas especializadas y eficientes de decisión en numerosas materias, considerando como un factor

\footnotetext{
70 PierCe (2007) pp. 118 y ss.

71 PiERCE (2007) p. 119.

72 Si se mira con atención esta decisión, incluso va más allá que lo que cincuenta años antes se había sostenido en Crowell $v$. Benson, al no requerir ni siquiera en estos casos que se salvaguarde la posibilidad de revisión judicial por los tribunales del artículo III de la Constitución Federal. PIERCE (2007) pp. 120 y ss.

73478 U.S. 835 (1986) p. 850, cit. por PIERCE (2007) p. 122.
} 
especialmente relevante para la salvaguardia del primero la existencia de revisión judicial (por cortes del artículo III) ${ }^{74}$.

Aunque no se pueda afirmar que se haya consolidado una línea decisoria estable -como sostiene un autor, "parece difícil armonizar los casos e incluso predecir cuál será la tendencia en esa área del derecho" -75 , la perspectiva abierta por la última sentencia citada ha generado algunos planteamientos doctrinales significativos, que intentan precisar los factores relevantes para determinar si la atribución de funciones de adjudicación a tribunales legislativos y agencias administrativas resulta respetuosa de la independencia judicial. Paul Verkuil destaca, por ejemplo, la relevancia de las garantías procesales y orgánicas previstas en los estatutos normativos de los tribunales legislativos y agencias administrativas para asegurar un juicio imparcial e independiente $^{76}$. Especial relevancia cobran, desde esa perspectiva, los esfuerzos legislativos, desarrollados en sucesivas reformas a la Administrative Procedure Act, para diferenciar y separar las funciones de adjudicación al interior de las agencias, atribuyéndolas a funcionarios -los Administrative Law Judges- dotados de un estatus de efectiva separación e independencia respecto de los vértices políticos de la administración ${ }^{77}$.

Otros autores destacan en cambio la relevancia para la protección de la independencia, de la preservación de una vía de revisión judicial de lo resuelto por la legislative court o la agencia administrativa ante una corte que satisfaga las exigencias del artículo III, de modo que ellas retengan el poder judicial "esencial"78. En un sentido semejante, aunque con el énfasis puesto no en la revisión sino otras formas de sujeción a la supremacía de la Corte Suprema, como la vinculación a sus precedentes, Pfander propone como criterio de legitimidad constitucional el que los tribunales y agencias con potestades de adjudicación que el Congreso cree sean configurados como tribunales inferiores -una expresión que utilizan tanto el artículo I como el artículo III de la Constitución federal-, sujetos a la supervisión y control de la Corte Suprema ${ }^{79}$.

Se diferencia así el sistema judicial de los Estados Unidos de Norteamérica del chileno por una mayor preocupación por la independencia judicial que en Chile. Si bien todavía en el país del norte hay casos de adjudicación de conflictos entre particulares que realizan órganos que no gozan de independencia respecto de los poderes políticos,

\footnotetext{
${ }^{74}$ La opinión de mayoría consideró también relevante el que el demandante, al reclamar voluntariamente ante la agencia, hubiera "renunciado" a su derecho a una adjudicación imparcial e independiente, aunque sugirió, frente a los jueces disidentes, que este no era el argumento decisivo, sino un argumento a mayor abundamiento, que podría ser abandonado en casos futuros. PIERCE (2007) pp.122.

75 Fox (2008) p. 81. A las fluctuaciones jurisprudenciales antes descritas se suma la reaparición de la distinción entre private y public rights, como determinante para evaluar la legitimidad constitucional de legislative courts y agencias administrativas con poderes de adjudicación, ahora desde el punto de vista del derecho a un juicio por jurado, garantizado por la Séptima Enmienda (con una opinión de mayoría redactada por el juez Brennan, el mismo que redactara la opinión plural en Northern Pipeline). Granfinanciera, S.A. v. Nordberg (492 U.S. 33 [1989]), en SCHWARTZ (1991) pp. 82 ss.

76 VERKUIL (1988).

77 MARCHETTI (2005) pp. 76 y ss.

78 Por ejemplo, FALLON (1988) y SCHWATRZ (1991), pp. 84 y ss.

79 PFANDER (2004)
} 
hay muchos asuntos que en Chile serían fallados por el Ejecutivo (Ministros, Superintendencias, servicios públicos), pero allá son competencia de agencias administrativas independientes de los poderes políticos. Por otra parte, a diferencia de nuestra Corte Suprema y de nuestro Tribunal Constitucional, que en sus opiniones mayoritarias han considerado absolutamente legítimo que órganos que carecen de independencia de los poderes políticos ejerzan jurisdicción, la Corte Suprema estadounidense ha considerado algunas veces la inconstitucionalidad de tal modelo jurisdiccional, discusión que todavía no se resuelve de una manera clara y definitiva.

\section{CONCLUSIONES}

Lo que acerca a países de diversas tradiciones institucionales y diversa cultura administrativa y jurídica, expresados en este trabajo en una confrontación entre Europa continental (España e Italia) y los Estados Unidos de Norteamérica, es que junto a la típica función judicial de resolver causas civiles y criminales que recae sobre lo que podríamos denominar tribunales ordinarios de justicia organizados bajo el principio de independencia judicial, se busca sedes políticamente neutrales, supra partes, para ejercitar actividades de composición de conflictos o de control de las actividades públicas referidas a temas en los que están presentes los intereses de la Administración, entes regulados y ciudadanos. En algunos casos se entrega a jueces ordinarios o pertenecientes al Poder Judicial el conocimiento de los asuntos contencioso-administrativos, como ocurre en España. En otros casos se recurre a la figura de agentes que no pertenecen a la judicatura que pueden fallar el asunto con mayor conocimiento técnico, pero siempre ajenos a los intereses de las partes de la causa. Hemos visto que ello es especialmente relevante en el caso de los Estados Unidos de Norteamérica, aunque todavía hay casos en que lo que podría ser definido como Gobierno central (departaments) adjudica conflictos. En el caso de Italia es más compleja la situación puesto que junto al caso de jueces especiales independientes que resuelven el contencioso-administrativo (Tribunales Administrativos Regionales y Consejo de Estado), se suman también casos de agencias independientes similares a las que existen en los Estados Unidos de Norteamérica.

En todos los casos que analizamos como muestras de derecho comparado (España, Estados Unidos de Norteamérica e Italia) la función judicial de resolver las causas civiles y criminales aparece legitimada por la independencia judicial que significa fundamentalmente sujeción solo a la ley. Pero cuando pensamos en conflictos en los que aparecen involucrados los órganos políticos, con especial referencia a la Administración del Estado, la legitimación del órgano juzgador es doble: por un lado el que ya vimos de independencia, o quizá ahora también de neutralidad política. Por otro, una legitimidad del saber que dan los expertos o técnicos de los asuntos administrativos que deben resolver.

En el caso de Chile hemos visto que los tribunales que resuelven los contenciosos civiles estrictamente considerados y algunas otras causas civiles en un sentido amplio como ocurre por ejemplo con las causas laborales, así como las criminales, están perfectamente regulados como tribunales independientes sujetos a un mismo estatuto orgánico. Sin embargo, algunos de los órganos que resuelven asuntos civiles en un sentido 
amplio, como sucede con los de orden administrativo, están vinculados a los órganos políticos y administrativos (caso del Ministro de Transportes y Telecomunicaciones y del cuestionado Director Regional del Servicio de Impuestos Internos, por ejemplo), por lo que solo se da el primer aspecto legitimador, el del conocimiento técnico. Falta, no obstante, en esos casos el segundo elemento legitimador que parece ser esencial para el ejercicio de la función jurisdiccional, cual es el de independencia. En otros casos no se trata de órganos que dependen directamente de los poderes políticos activos, por lo que no hay una dependencia directa del poder político. Con todo, su regulación orgánica no permite asumir una clara presunción que fallarán imparcialmente y, desde luego, están regulados de un modo inorgánico y desigual que aleja de toda aproximación a los valores de la seguridad jurídica y la igualdad jurídica.

España resultó ser el país con el Poder Judicial más unitario o concentrado de los casos examinados, por lo que se puede suponer que cuenta con la organización judicial con mayor autonomía respecto de los poderes políticos. No se examinó en este trabajo la composición del órgano de gobierno del Poder Judicial (Consejo General del Poder Judicial), lo que podría conspirar contra la afirmación recientemente expuesta. A ello debe agregarse el hecho de que los jueces españoles, todos, cuentan con garantías muy fuertes para asegurar la independencia judicial. En el caso de Estados Unidos de Norteamérica y de Italia hay una mayor fragmentación en la organización judicial, pero pese a ello hay mecanismos institucionales para asegurar la independencia de los juzgadores, especialmente en Italia. Y ello es lo esencial en esta materia. La unidad y exclusividad judicial no son valores abstractos, sino que deben permitir la configuración de una presunción razonable de un ejercicio imparcial de la jurisdicción, algo que tanto en los Estados Unidos de Norteamérica como en Italia está normalmente asegurado. Chile, en comparación con los casos examinados, resultó ser no solo un país con alto poder de fragmentación en la organización judicial, sino también por no tener siempre asegurada la independencia del juzgador y no permitir siempre la configuración de la presunción de imparcialidad judicial. Se puede concluir entonces que la situación chilena dista mucho de ser satisfactoria y requiere de una completa reingeniería legislativa.

\section{BIBLIOGRAFÍA CITADA}

ANDRIOLI, Virgilio (1992): Studi sulla giustizia costituzionale (Milán, Giuffrè) 589 pp. BANDrÉS, José Manuel (1987): Poder Judicial y Constitución (Barcelona, Bosch) 84 pp. BATOR, Paul M. (1990): "The Constitution as architecture: legislative and administrative courts ander article III”, Indiana Law Journal, vol. 65: pp. 233-275.

Bonifacio, Franco y GiacobBe, Giovanni (1986): La magistratura. Commentario della Costituzione (Bolonia, Zanichelli-Il Foro Italiano) tomo III, $179 \mathrm{pp}$.

BORDALÍ, Andrés (2003): “Independencia y responsabilidad de los jueces", Revista de Derecho Universidad Austral de Chile, vol. XIV - julio: pp. 159-174.

Bordalí, Andrés (2005): "Principios de una nueva justicia administrativa en Chile", en: FERradA, Juan Carlos, La justicia administrativa (Universidad Austral de Chile, LexisNexis) pp. 341-381. 
Bordalí, Andrés (2006): "La Administración Pública ante los tribunales de justicia chilenos", Revista Chilena de Derecho, vol. 33, No 1: pp. 17-36.

BORDALÍ, Andrés (2007a): "La independencia del poder judicial en el sistema constitucional chileno”, en: Romero Seguel, Alejandro, Estudios de Derecho en homenaje a Raúl Tavolari Oliveros (Santiago de Chile, LexisNexis) pp. 509-528.

Bordalí, Andrés (2007b): "Análisis crítico de la función e independencia judicial en el Derecho chileno", ATRIA, Fernando y COUSO, Javier (editores), La judicatura como organización (Santiago de Chile, Expansiva - Instituto de Estudios Judiciales) pp. 57-82.

BORDALÍ, Andrés (2008): "La doctrina de la separación de poderes y el poder judicial chileno", Revista de Derecho Pontificia Universidad Católica de Valparaíso, XXX Semestre I: pp. 185-219.

Bordalí, Andrés y FERradA, Juan Carlos (2008): Estudios de justicia administrativa (Santiago de Chile, LexisNexis) 233 pp.

Caballero, Felipe (2005): "El artículo 324 del Código Orgánico de Tribunales y el principio de igualdad en el ordenamiento jurídico chileno", Revista de Derecho Universidad Austral de Chile, vol. XVIII, No 2: pp. 155-166.

Clarich, Marcello (2005): Autorità indipendenti. Bilancio e prospettive di un modello (Bolonia, Il Mulino) 206 pp.

Colombo, Juan (2004): La competencia (Santiago, Editorial Jurídica de Chile) 657 pp.

De OтTO, Ignacio (1989): Estudios sobre el Poder Judicial (Madrid, Ministerio de Justicia) $248 \mathrm{pp}$.

EvANS, Enrique (2004): Los derechos constitucionales (Santiago, Editorial Jurídica de

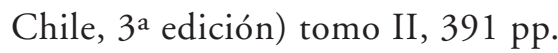

FALLON, Richard H. Jr. (1988): "Of legislative courts, administrative agencies and article III”, Harvard Law Review, vol. 101, No 5: pp. 915-999.

Ferrajoli, Luigi (2007a) Principia iuris. Teoria del diritto e della democrazia. 1. Teoria del diritto (Roma-Bari, Laterza) $1.021 \mathrm{pp}$.

Ferrajoli, Luigi (2007b): Principia iuris. Teoria del diritto e della democrazia. 2. Teoria della democrazia (Roma-Bari, Laterza) 713 pp.

FOX, William (2008): Understanding Administrative Law (San Francisco, LexisNexis) $471 \mathrm{pp}$.

GUARnieri, Carlo (1981): L'indipendenza della magistratura (Padua, Cedam) 235 pp.

GUARnieri, Carlo y PEDERZOLI, Patrizia (2002): La magistratura nelle democrazie contemporanee (Roma-Bari, Laterza) 214 pp.

GUASP, Jaime (1985): La pretensión procesal (Madrid, Civitas) $101 \mathrm{pp}$.

GuAstini, Riccardo y Pizzorusso, Alessandro (1994): La Magistratura. Commentario della Costituzione (Bolonia, Zanichelli - Il Foro Italiano) 250 pp.

HazARD, Geoffrey y TARUfFo, Michele (1993): La giustizia civile negli Stati Uniti (Bolonia, Il Mulino) 270 pp.

Hernando, Francisco José (2003): "Poder Judicial y Constitución”, en: Constitución y Poder Judicial. XXV Aniversario de la Constitución de 1978 (Madrid, Consejo General del Poder Judicial) pp. 7-28. 
Mandrioli, Crisanto (2000): Corso di Diritto Processuale Civile I. Nozioni introduttive e disposizioni generali (Turín, Giappichelli) 284 pp.

MarchetTi, Barbara (2005): Pubblica Amministrazione e corti negli Statu Uniti. Il judicial review sulle administrative agencies (Padua, Cedam) $332 \mathrm{pp.}$

Martínez Alarcón, María Luz (2004): La independencia judicial (Madrid, Centro de Estudios Políticos y Constitucionales) 425 pp.

Moreno Catena, Víctor, et al. (2005): Manual de organización judicial (Valencia, Tirant lo Blanch) 446 pp.

MuÑOZ, Natalia (2007): "Facultades de control jurisdiccional radicadas en entes ajenos al Poder Judicial. Consideraciones críticas acerca de estas competencias", en: PANTOJA, Rolando (coordinador), Derecho administrativo chileno (México D. F., Editorial Porrúa) pp. 849-972.

Nieto, Alejandro (2005): El desgobierno judicial (Madrid, Trotta) 301 pp.

PEDRAZ, Ernesto (1993): Privilegios de las administraciones públicas en el proceso civil (Madrid, Civitas) 248 pp.

Pereira, Hugo (1996): Curso de Derecho Procesal. Derecho Procesal Orgánico (Santiago de Chile, Conosur) 496 pp.

PFANDER, James E. (2004): "Article I tribunals, article III courts and the judicial power of the United States", Harvard Law Review, vol. 118, No 2: pp. 643-777.

PIERCE, Richard (2007): Administrative Law Treatise (Nueva York, Aspen Law \& Business) $135 \mathrm{pp}$.

Politoff, Sergio, Matus, Jean Pierre y Ramírez, María Cecilia (2004): Lecciones de Derecho Penal Chileno. Parte especial (Santiago, Editorial Jurídica de Chile) 661 pp.

REQUEJO, Juan Luis (1989): Jurisdicción e independencia judicial (Madrid, Centro de Estudios Constitucionales) 262 pp.

RICCI, Gian Franco (2001): Principi di Diritto Processuale Generale (Turín, Giappichelli) 409 pp.

SCHWARTZ, Bernard (1991): Administrative Law (Boston, Little, Brown and Company) 106 pp.

VERKUIL, Paul (1988): "Separation of powers, the rule of law and the idea of independence", William and Mary Law Review, vol. 30. 